\title{
Humeral metastasis from a sacrococcygeal chordoma: a case report
}

\author{
Negar Azarpira ${ }^{*}$, Said Solooki ${ }^{2}$, Sepideh Sepidbakht ${ }^{3}$ and Ramin Mardani ${ }^{1}$
}

\begin{abstract}
Introduction: Chordomas are rare tumors of the skeletal system that arise from an intra-osseous benign precursor of notochordal cells. They are mainly locally aggressive. However, metastases to other sites, including the humeri, resulting in pathological fractures have been reported. We report the case of a patient with a metastatic chordoma that produced a pathologic fracture of the humerus.

Case presentation: We report the case of a 60-year-old Iranian woman who presented with a fracture of her right humerus following a minor trauma. She had a history of a sacrococcygeal chordoma. Histological and immunohistochemical studies of the fracture site suggested the diagnosis of a chordoma.

Conclusions: Chordoma is a rare tumor and rarely metastasizes, but it should be considered in the differential diagnosis of epithelioid bone tumors. The only current effective treatment for this type of tumor is carbon ion therapy. There is currently no effective medical therapy available for advanced chordoma, and this type of tumor is not very responsive to radiotherapy.
\end{abstract}

\section{Introduction}

Chordomas are rare, low-grade, primary malignant bone tumors arising from primitive notochord remnants of the axial skeleton. The sacrum is the most common anatomical site of origin, accounting for $50 \%$ to $60 \%$ of all cases, followed by the skull base region (spheno-occipital and/or nasal), accounting for $25 \%$ to $35 \%$ of cases; the cervical vertebrae, accounting for approximately $10 \%$ of cases; and the thoracolumbar vertebrae, accounting for approximately $5 \%$ of cases [1-4].

These tumors are mainly locally aggressive, with a high incidence of local recurrence and a poor long-term prognosis. Metastatic lesions have been reported in the liver, lungs, lymph nodes, peritoneum, skin, heart, humeri, brain, and distant regions of the spine [1-7].

\section{Case presentation}

A 60-year-old Iranian woman presented to our hospital with pain and swelling in her right arm following a minor fall. Our initial physical examination revealed her to be in a good general condition. She was normotensive, with a pulse rate of 92 beats/minute. Her other

\footnotetext{
* Correspondence: negarazarpira@yahoo.com

'Department of Pathology, Shiraz University of Medical Sciences, Shiraz, Iran Full list of author information is available at the end of the article
}

laboratory values were as follows: body temperature $37^{\circ}$ $\mathrm{C}$, hemoglobin $12.2 \mathrm{~g} / \mathrm{dL}$, leukocytes 22 cells $/ \mathrm{mm}^{3}$, platelets $200 \mathrm{U} / \mathrm{L}$, sodium $141 \mathrm{mEq} / \mathrm{L}$, potassium $4 \mathrm{mEq} / \mathrm{L}$, glucose $11.6 \mathrm{mmol} / \mathrm{L}$, blood urea nitrogen $15.1 \mathrm{mmol} / \mathrm{L}$, and creatinine $250 \mathrm{mmol} / \mathrm{L}$. A plain X-ray showed a pathologic fracture in the mid-shaft of her right humerus and a large, ill-defined soft tissue mass (Figure 1). Magnetic resonance imaging (MRI) showed a huge lobulated mass destroying the shaft of the humerus and displacing the surrounding soft tissue. The mass was bright on serial T2-weighted MRI scans and dark on serial T1-weighted MRI scans, with marked enhancement after a gadolinium injection (Figure 2). Four years ago she had been treated for a sacrococcygeal chordoma with surgical resection and post-operative radiotherapy. A local tumor recurrence developed after one year and required additional surgical procedures. A histological examination of the biopsy from the humeral lesion showed a lobulated mass composed of cuboidal to polygonal cells with eccentric nuclei, clear to eosinophilic cytoplasm, and pools of extracellular mucin (arrow in Figure 3). Typically, few tumor cells have a "physaliferous" (bubble-bearing) appearance. On the basis of these findings, we considered differential diagnoses such as myxoid chondrosarcoma, myxoid liposarcoma, primary
C Biomed Central

C 2011 Azarpira et al.; licensee BioMed Central Ltd. This is an open access article distributed under the terms of the Creative Commons Attribution License (http://creativecommons.org/licenses/by/2.0), which permits unrestricted use, distribution, and reproduction in any medium, provided the original work is properly cited. 


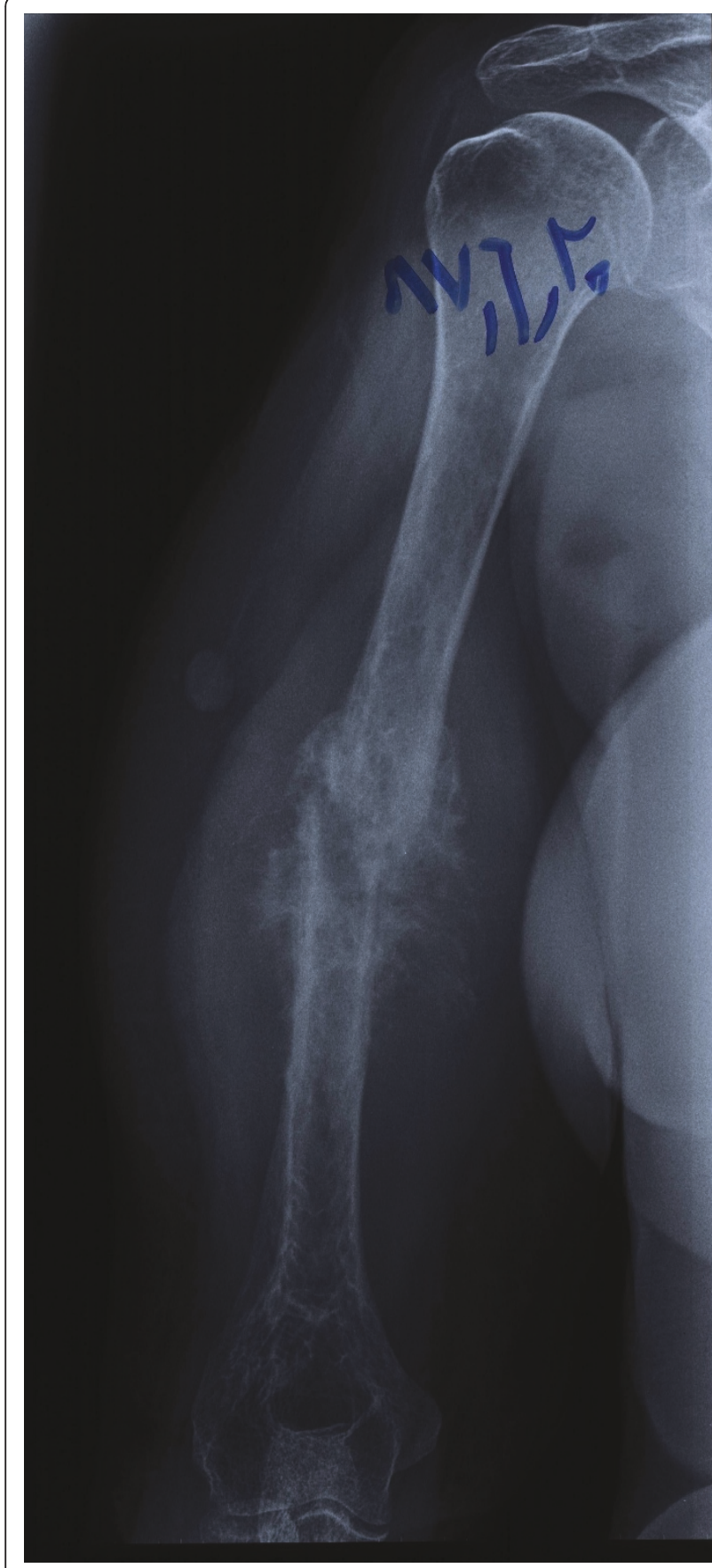

Figure 1 Plain radiograph showing a tumor characterized by a fracture in the mid-shaft of the right humerus with a large soft tissue mass.

mixed tumor of the bone, metastasizing pleomorphic adenoma of the salivary gland, metastatic renal cell carcinoma (RCC), or metastatic carcinoma with intra-cytoplasmic mucin from the colon or lung [8,9]. Most metastatic carcinomas have more of the cytological features of malignancy than chordomas do. The tumor

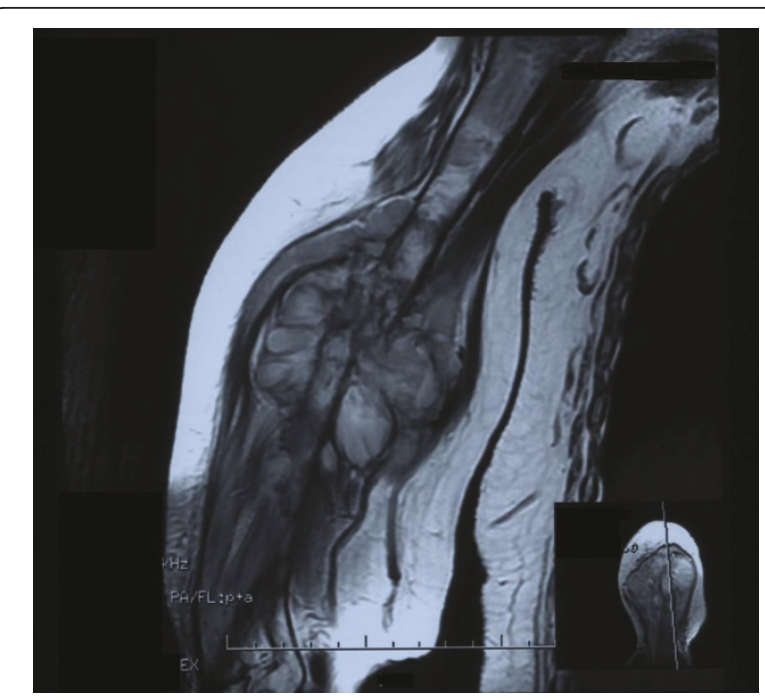

Figure 2 Magnetic resonance imaging scan showing extensive soft tissue mass with bone destruction of the left humerus.

cells stained positive for AE1/3 (Figure 4), ethidium monoazide (EMA), S100, and vimentin. Although both chordomas and chondrosarcomas stain with S100 protein, myxoid chondrosarcomas do not stain with keratin and EMA. Additional immunochemistry was performed for CD10, the results of which were negative in this case and usually expressed in RCC. Abdominal and pelvic ultrasonography and computed tomography (CT) of her chest and abdomen were normal. On the basis of this evidence and our review of the original histology following her previous chordoma excision (which was histologically identical to the humeral lesion), a diagnosis of

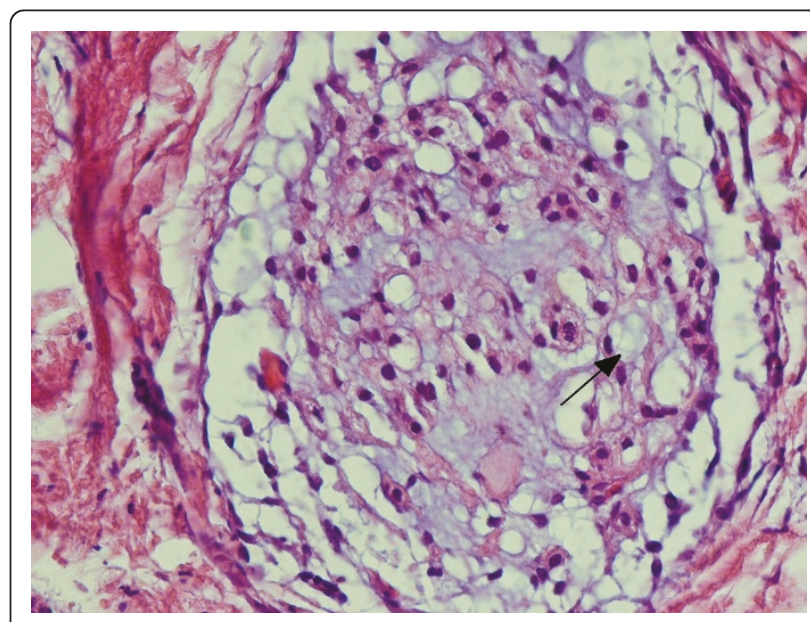

Figure 3 Typical lobulated appearance of a chordoma with small nests of tumor cells on a pale blue myxoid background. Prominent intra-cytoplasmic vacuolization can be seen (arrow) (hematoxylin and eosin stain, $\times 100$ ). 


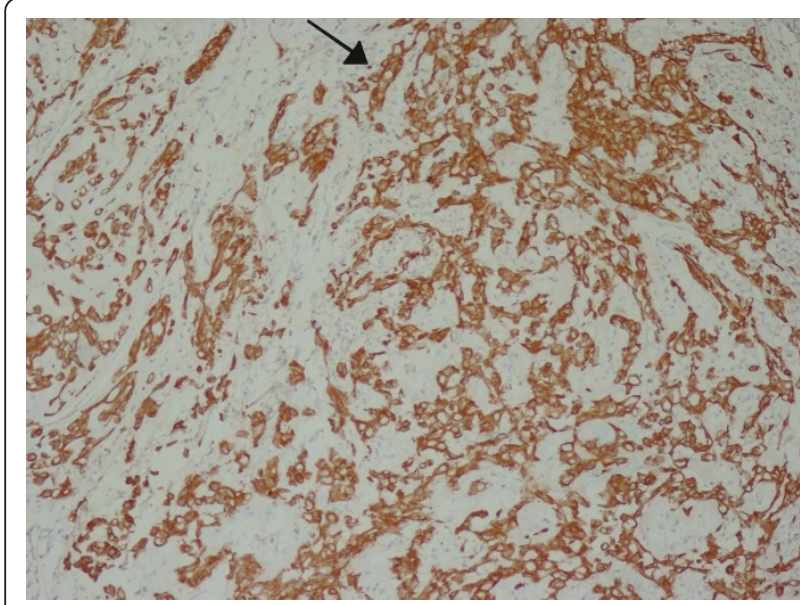

Figure 4 The tumor cells show strong reactivity with antibodies to ethidium monoazide (arrow) (original

magnification, $\times 100$ )

metastatic chordoma was confirmed. She refused any active treatment.

\section{Discussion}

Chordomas arise from the remnant of the fetal notochord and grow slowly. The most common location is the sacrococcygeal region. This tumor is generally reported in adults; most patients are in the fifth to seventh decades of life [10-12]. Classic radiological findings for chordoma are a bony lytic lesion with an accompanying soft tissue mass. The sacrococcygeal lesions are known to metastasize more frequently than the other types, and radiation therapy raises the risk of metastasis. Despite all the available modalities of treatment, the prognosis for this condition remains poor because of the difficulty in gaining surgical clearance and the tumor's propensity to metastasize [11]. Histologically, mitoses and anaplasia can be present in chordomas without adversely affecting the duration of a patient's survival. Previous studies have found that many of the metastatic lesions were asymptomatic or were found during post-mortem examination, which suggests that metastases from chordomas could be considered indolent in these cases $[4,5]$. Our patient had an asymptomatic rib lesion as well as a large humeral metastasis with pathologic fracture. A pathological analysis of the metastatic tumor revealed features identical to the primary tumor. Metastasis to the long bones is a rare phenomenon.

The biological behavior of chordomas differs from patient to patient. Some patients harbor tumors capable of aggressive behavior both locally and distantly, while others have tumors that behave more indolently. There is no good method for predicting the behavior of individual chordomas $[4,11]$. Therefore, it seems that aggressive surgical resection with local adjuvant treatment, such as carbon ion therapy, must be undertaken to prevent the development of recurrent lesions and metastatic neoplasms.

\section{Conclusions}

Chordomas are rare tumors. They are relatively radioresistant, and currently there is no effective medical therapy for treating them. Complete local excision is the most effective treatment for achieving a long-term cure. Although these tumors rarely metastasize, they need to be considered in the differential diagnosis of metastatic epithelioid bone tumors.

\section{Consent}

Written informed consent was obtained from the patient for publication of this case report and any accompanying images. A copy of the written consent is available for review by the Editor-in-Chief of this journal.

\footnotetext{
Author details

${ }^{1}$ Department of Pathology, Shiraz University of Medical Sciences, Shiraz, Iran. ${ }^{2}$ Department of Orthopedics, Shiraz University of Medical Sciences, Shiraz, Iran. ${ }^{3}$ Department of Radiology, Shiraz University of Medical Sciences, Shiraz,
} Iran.

\section{Authors' contributions}

NA participated in the histology-related issues and drafted the manuscript. SSo contributed to all of the surgical aspects of patient care and revised the respective sections in the manuscript. SSe participated in the radiological aspects of the case and provided input to the case discussion. RM contributed to the review of the literature and provided clinical insights. All authors read and approved the final manuscript.

\section{Competing interests}

The authors declare that they have no competing interests.

Received: 18 September 2009 Accepted: 1 August 2011

Published: 1 August 2011

\section{References}

1. Resnik CS, Young JW, Levine AM, Aisner SC: Case report 544: metastatic chordoma to humeri (originating in sacrum). Skeletal Radiol 1989, 18:303-305.

2. Mirra J, Nelson S, Della Rocca C, Mertens F: Chordoma. In Pathology and Genetics of Tumours of Soft Tissue and Bone. Edited by: Fletcher CD, Unni K, Mertens F. Lyon: IARC Press; 2002:316-317.

3. McMaster ML, Goldstein AM, Bromley CM, Ishibe N, Parry DM: Chordoma: incidence and survival patterns in the United States, 1973-1995. Cancer Causes Control 2001, 12:1-11.

4. Ferraresi V, Nuzzo C, Zoccali C, Marandino F, Vidiri A, Salducca N, Zeuli M, Giannarelli D, Cognetti F, Biagini R: Chordoma: clinical characteristics, management and prognosis of a case series of 25 patients. BMC Cancer 2010, 10:22

5. Kaiser TE, Pritchard DJ, Unni KK: Clinicopathologic study of sacrococcygeal chordoma. Cancer 1984, 54:2574-2578.

6. Kamel MH, Lim C, Kelleher M, Aquilina K, Keohane C, Kaar G: Intracranial metastasis from a sacrococcygeal chordoma: case report. J Neurosurg 2005, 102:730-732

7. Yonemoto $T$, Tatezaki S, Takenouchi $T$, Ishii $T$, Satoh $T$, Moriya H: The surgical management of sacrococcygeal chordoma. Cancer 1999, 85:878-883. 
8. Rose AG, Heselson NG, Marks RK, Kranold D: Case report 720: multicentric mixed tumor of bone with pulmonary involvement. Skeletal Radiol 1992, 21:140-145.

9. Manucha V, loffe OB: Metastasizing pleomorphic adenoma of the salivary gland. Arch Pathol Lab Med 2008, 132:1445-1447.

10. Vergara G, Belinchón B, Valcárcel F, Veiras M, Zapata I, de la Torre A: Metastatic disease from chordoma. Clin Trans/ Oncol 2008, 10:517-521.

11. McPherson CM, Suki D, McCutcheon IE, Gokaslan ZL, Rhines LD, Mendel E: Metastatic disease from spinal chordoma: a 10-year experience. $J$ Neurosurg Spine 2006, 5:277-280.

12. Boriani S, Bandiera S, Biagini R, Bacchini P, Boriani L, Cappuccio M, Chevalley F, Gasbarrini A, Picci P, Weinstein JN: Chordoma of the mobile spine: fifty years of experience. Spine 2006, 31:493-503.

doi:10.1186/1752-1947-5-339

Cite this article as: Azarpira et al:: Humeral metastasis from a

sacrococcygeal chordoma: a case report. Journal of Medical Case Reports 2011 5:339.

\section{Submit your next manuscript to BioMed Central} and take full advantage of:

- Convenient online submission

- Thorough peer review

- No space constraints or color figure charges

- Immediate publication on acceptance

- Inclusion in PubMed, CAS, Scopus and Google Scholar

- Research which is freely available for redistribution

Submit your manuscript at www.biomedcentral.com/submit 